\title{
FORMULATION OPTIMIZATION OF PROMETHAZINE THEOCLATE IMMEDIATE RELEASE PELLETS BY USING EXTRUSION-SPHERONIZATION TECHNIQUE
}

\author{
SHELAR VISHWAS S. ${ }^{a}$, SHIROLKAR SATISH V ${ }^{\text {a }}$, KALE RUPALI N. ${ }^{{ }^{*}}$ \\ aDepartment of Pharmaceutics, Dr. D. Y. Patil Institute of Pharmaceutical Sciences and Research Centre, Pimpri, Pune 411018 \\ Email: rupalikale07@gmail.com
}

Received: 30 May 2017, Revised and Accepted: 28 Nov 2017

\begin{abstract}
Objective: Promethazine theoclate is a BCS Class II drug having anti-histaminic property and mainly used for the treatment of motion sickness and postoperative emesis. The main objective of the research work was to formulate and optimize immediate release pellets of promethazine theoclate by using the extrusion-spheronization technique to offer immediate release dosage form suitable for treatment of nausea and vomiting associated with motion sickness and post-operative conditions.
\end{abstract}

Methods: Immediate release pellets of promethazine theoclate were prepared by using microcrystalline cellulose (MCC) and corn starch as filler and disintegrant respectively along with other excipients. Pellet formulation was further optimized for bulk density, disintegration time and percent drug release after $10 \mathrm{~min}$. using $3^{2}$ factorial design. Formulations were also characterized for drug-polymer interactions using Differential Scanning Calorimetry (DSC), surface morphology by Scanning Electron Microscopy (SEM) and other physicochemical properties.

Results: Optimised pellet formulation contains 2.5:4.5:1 ratio of MCC: Corn Starch: Drug and spheronization time of 60 seconds showing highest percent yield of $78 \%$ and immediate drug release of $100.52 \pm 0.65 \%$ after $10 \mathrm{~min}$.

Conclusion: Promethazine theoclate pellets formulated in this study can serve as an alternative to tablet dosage form which can give immediate drug release for treatment of motion sickness and postoperative emesis.

Keywords: Promethazine theoclate, Immediate release pellets, Multiparticulate drug delivery, Extrusion-spheronisation, Factorial design

(C) 2018 The Authors. Published by Innovare Academic Sciences Pvt Ltd. This is an open access article under the CC BY license (http://creativecommons.org/licenses/by/4.0/) DOI: http://dx.doi.org/10.22159/ijap.2018v10i1.20350

\section{INTRODUCTION}

Promethazine theoclate is BCS Class II, $\mathrm{H}_{1}$ antihistaminic drug mainly used in the treatment of motion sickness and postoperative emesis [1, 2]. It has $25 \%$ bioavailability due to its poor aqueous solubility which is the major limiting factor for its absorption and delayed onset of action [3]. Promethazine theoclate tablets are available in the market as immediate release single-unit dosage form for oral administration. Formulation development of transdermal patch, SLN, suppository and gel for promethazine theoclate are also explored in research for different routes of administration [4-6].

Pellets formulation as multiple-unit dosage forms are preferred over single-unit dosage forms due to stable plasma profiles, free dispersion in GI tract maximizing GI absorption and minimizing local mucosal side effects. Among the various types of multiple-unit dosage forms, pellets have attracted more attention due to their unique clinical and technical advantages. Pellet drug delivery system offers various therapeutic advantages such as dose tailoring as well as it helps in reducing inter and intrapatient variability by reducing fluctuations in peak plasma concentrations with no significant reduction in bioavailability $[7,8]$.

Microcrystalline cellulose (MCC) and Corn starch are most common excipients utilized for the production of pellets via extrusion spheronisation technique. It has ideal rheological properties well suited for the process $[9,10]$. In case of a drug having low solubility, MCC alone can give prolonged drug release prøil e [11] due to the lack of disintegration of MCC-based pellets. It may also show drug adsorption onto the surface of MGibr e $[12,13]$ which can be minimized by using Corn starch in combination with MCC [14] to get an immediate release of the drug.

The objective of this study was to formulate promethazine theoclate immediate release pellets using MCC and Corn starch and optimize the formula using $3^{2}$ factorial design.

\section{MATERIALS AND METHODS}

\section{Materials}

Promethazine theoclate was obtained as a gift sample from Mehta Pharmaceutical Pvt. Ltd., Mumbai. Microcrystalline cellulose (Avicel
PH101) was purchased from Research Lab, Mumbai. Corn starch, sodium starch glycolate, lactose (monohydrate), isopropyl alcohol and $\mathrm{HCl}$ were purchased from Loba Chemie, Mumbai. Polyvinylpyrrolidone (PVP) K-30 was purchased from Himedia Laboratories Pvt. Ltd., Mumbai.

\section{Methods}

Construction of calibration curve of promethazine theoclate in 0.1 N HCl

Accurately weighed $10 \mathrm{mg}$ of the promethazine theoclate was dissolved in $10 \mathrm{ml}$ methanol and diluted to $100 \mathrm{ml}$ with $0.1 \mathrm{~N} \mathrm{HCl}$. The prepared stock solution was subsequently diluted to get the concentrations of 5 , $10,15,20,25,30,35,40,45,50$ and $55 \mu \mathrm{g} / \mathrm{ml}$ of promethazine theoclate respectively. The absorbance of these solutions was measured at $278 \mathrm{~nm}$ using UV/Visible spectrophotometer (Shimadzu). Calibration curve was plotted as shown in fig. 1.

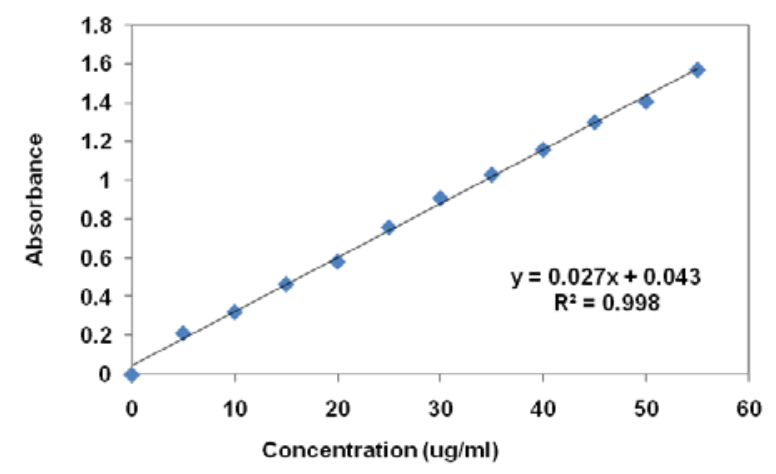

Fig. 1: Calibration curve of promethazine theoclate in $0.1 \mathrm{~N} \mathrm{HCl}$

\section{Drug-excipient compatibility study}

Investigation of the potential interaction of promethazine theoclate and other excipients was done by recording and analysing 
thermograms using DSC (DSC 60 Shimadzu, Japan) for pure drug and physical mixture of the drug with excipients. Samples were heated at a heating rate of $10^{\circ} \mathrm{C} / \mathrm{min}$. in the range of $25-400{ }^{\circ} \mathrm{C}$ using standard aluminium sample pans. DSC thermograms were observed for potential interactions.

\section{Preparation of pellet formulation by extrusion-spheronization technique}

\section{Preliminary screening of excipients}

Preliminary screening for selection of binder, other excipients and instrument parameters was done by visual inspection and flow properties of the pellets obtained from the initial studies. It was observed that PVP K30, as a binder, gave acceptable spherical pellets with good yield, low friability and satisfactory flow properties. Based on the observations, 7\% of PVP K30, 8\% of SSG and speed of 800rpm with 5 $\mathrm{mm}$ friction plate were selected as formulation and process parameters.

\section{Preparation of drug-loaded pellets}

Pellets were prepared by following steps using lab scale spheronizer (Shakti Pharmatech).

\section{Preparation of wet mass}

The powder mixture was prepared by homogenous blending of microcrystalline cellulose, corn starch, PVP K-30 and sodium starch glycolate. Binder solution containing PVP K30 in a mixture of purified water and isopropyl alcohol was added separately to dry mixture with kneading. Successive pauses were taken for the addition of the liquid components for proper kneading to obtain a damp mass of appropriate consistency for the extrusion process $[10,11]$.

\section{Extrusion}

Prepared wet mass was immediately extruded through sieve number 14 (B. S. S.) to get compact cylindrical extrudates of uniform diameter.

\section{Spheronization}

The extrudates were spheronised using lab Spheronizer (Shakti Pharmatech) at $800 \mathrm{rpm}$ with $5 \mathrm{~mm}$ friction plate to get spherical pellets. Wet pellets were dried in Fluid Bed Dryer (FBD) for $10 \mathrm{~min}$ keeping product temperature below $65^{\circ} \mathrm{C}$.

\section{Formula optimization}

Preliminary studies showed a significant effect of concentration of MCC and Corn starch on bulk density, disintegration time and percent drug release of pellets. These two parameters were selected as Independent variables for the formulation optimization of promethazine theoclate loaded pellets using $3^{2}$ factorial design. Nine batches were prepared at levels of-1, $0,+1$ of independent variables as shown in table 1.

Table 1: Composition of promethazine theoclate pellets for factorial design

\begin{tabular}{lllllll}
\hline Batch code & MCC (g) & Corn starch (g) & Lactose (g) & SSG (g) & PVP K-30 (g) & Drug (g) \\
\hline I & 3 & 7 & 4.25 & 2 & 1.75 & 2 \\
II & 3 & 8 & 3.25 & 2 & 1.75 & 2 \\
III & 3 & 9 & 2.25 & 2 & 1.75 & 2 \\
IV & 4 & 7.25 & 2 & 1.75 & 2 \\
V & 4 & 8 & 2.25 & 2 & 1.75 & 2 \\
VI & 4 & 9 & 2.25 & 2 & 1.75 & 2 \\
VII & 5 & 7 & 1.25 & 2 & 1.75 & 2 \\
VIII & 5 & 8 & 0.25 & 2 & 1.75 & 2 \\
IX & 5 & 9 & & 2 & 1.75 & 2 \\
\hline
\end{tabular}

All batches were evaluated for response variables, bulk density, disintegration time and percent drug release. The data obtained was analyzed using Design Expert 7.0.0 software to generate polynomial equation, contour plots and design space.

\section{Characterization of drug loaded pellets}

Developed formulations of pellets were characterized for the following properties.

\section{Particle size}

Photomicrograph of pellets was taken and analysed using Image J software to determine its particle size.

\section{Morphology}

The surface morphology of pellets was examined using the scanning electron microscope (FEI Nova NanoSEM 450) which was operated at $3.0 \mathrm{kV}$ and $5.0 \mathrm{kV}$ at magnifications of 103X, 250X, 1000X and 5000X.

\section{Bulk density}

Apparent bulk density is determined by pouring a weighed quantity of pellets into a graduated cylinder and measuring the volume and weight. Bulk density is calculated using the following formula:

$$
\text { Bulk density }=\frac{\text { Weight of pellets }}{\text { Bulk volume of pellets }}
$$

\section{Hardness}

The hardness of pellets was measured by using a digital pellet hardness tester (Veego).

\section{Friability [16]}

Friability of pellets was checked by using Friability test apparatus (Roche Friabilator) at $25 \mathrm{rpm}$ for $4 \mathrm{~min}$. Percent friability was calculated by the equation below after removing fines from sieve no.36.

$$
\text { Friability }(\%)=\frac{W 1-W 2}{W 1} \times 100
$$

Where,

W1 = Initial weight of pellets

W2= Final weight of pellets after removing fines.

\section{Disintegration time}

The disintegration time of pellets was checked by putting $250 \mathrm{mg}$ of pellets in $50 \mathrm{ml}$ distilled water with continuous shaking in water bath shaker at $37^{\circ} \mathrm{C}$ till complete disintegration.

\section{Drug content}

About $250 \mathrm{mg}$ of the pellets were taken and crushed in a mortar to obtain a fine powder. $25 \mathrm{mg}$ powder was taken and dissolved in $10 \mathrm{ml}$ methanol and diluted up to $50 \mathrm{ml}$ with $0.1 \mathrm{~N} \mathrm{HCl}$ sonicated for $5 \mathrm{~min}$ and volume was made up to $100 \mathrm{ml}$ with $0.1 \mathrm{~N} \mathrm{HCl}$. The absorbance of the resulting solution was measured at $278 \mathrm{~nm}$ using the UV/Visible spectrophotometer.

The concentration of drug in solution was calculated using calibration curve.

Drug content (\%) was calculated using following formula:

$$
\text { Drug content }(\%)=\frac{\text { Actual amount of Promethazine theoclate found in pellets }}{\text { Theoretical amount of Promethazine theoclate in pellets }} \times 100
$$




\section{In vitro dissolution studies}

In vitro dissolution studies were performed using USP type 1 apparatus (basket). An accurately weighed sample of pellets containing an equivalent amount of $25 \mathrm{mg}$ of promethazine theoclate was filled into gelatine capsules and dissolution studies were carried out into $900 \mathrm{ml}$ of $0.1 \mathrm{~N} \mathrm{HCl}$, maintained at a temperature of $37^{\circ} \mathrm{C} \pm 0.5^{\circ} \mathrm{C}$ at $100 \mathrm{rpm}$. At different time intervals, $10 \mathrm{ml}$ aliquot of the sample was withdrawn and the volume was replaced with an equivalent amount of dissolution medium kept at $37^{\circ} \mathrm{C}$. The collected samples were filtered and the absorbance was measured at $278 \mathrm{~nm}$. Percent drug release was compared with drug release from marketed formulation (Avomine tablet; Promethazine theoclate $25 \mathrm{mg}$; Mfg. by: sanofi aventis).

\section{Stability studies of optimized batch}

Stability studies of the optimized formulations were performed using gelatin capsules filled with developed promethazine theoclate pellets at accelerated conditions of $40{ }^{\circ} \mathrm{C}$ temperature and $75 \% \mathrm{RH}$ for $30 \mathrm{~d}$ as per the International Conference on Harmonization (ICH) guidelines

Samples were withdrawn after $30 \mathrm{~d}$ and subjected to analysis for specified parameters.

\section{RESULTS AND DISCUSSION}

Drug-excipient compatibility studies for promethazine theoclate along with the excipients used in the formulation was checked using DSC technique. As shown in fig. 2, DSC thermogram of pure promethazine theoclate and physical mixture of the drug with excipients showed sharp endothermic peaks at $180.1{ }^{\circ} \mathrm{C}$ and 178.9 ${ }^{\circ} \mathrm{C}$ respectively, indicating no significant difference in peak position and compatibility of the drug with excipients.

The flow properties of pellets were evaluated by checking the angle of repose. An angle of repose $(\theta)<30^{\circ}$ indicates free-flowing material and $>40^{\circ}$ indicates poor flow. Values for the angle of repose $(\theta)$, for all factorial batches of pellets, were found to be in the range of $20.55^{\circ} \pm 0.02$ to $28.35^{\circ} \pm 0.02$ indicating free-flowing pellets which can be easily filled into capsules.

Percent friability of prepared pellets was found to be within $0.32 \pm 0.35$ to $0.80 \pm 0.19$ which was acceptable as the standard limit for percent friability which is $<1 \%$. It indicates sufficient mechanical integrity, strength and hardness. The particle size of all factorial batches was found within $0.87 \pm 0.42$ to $1.41 \pm 0.18 \mathrm{~mm}$. Data of evaluation of promethazine theoclate loaded pellets is shown in table 2 .

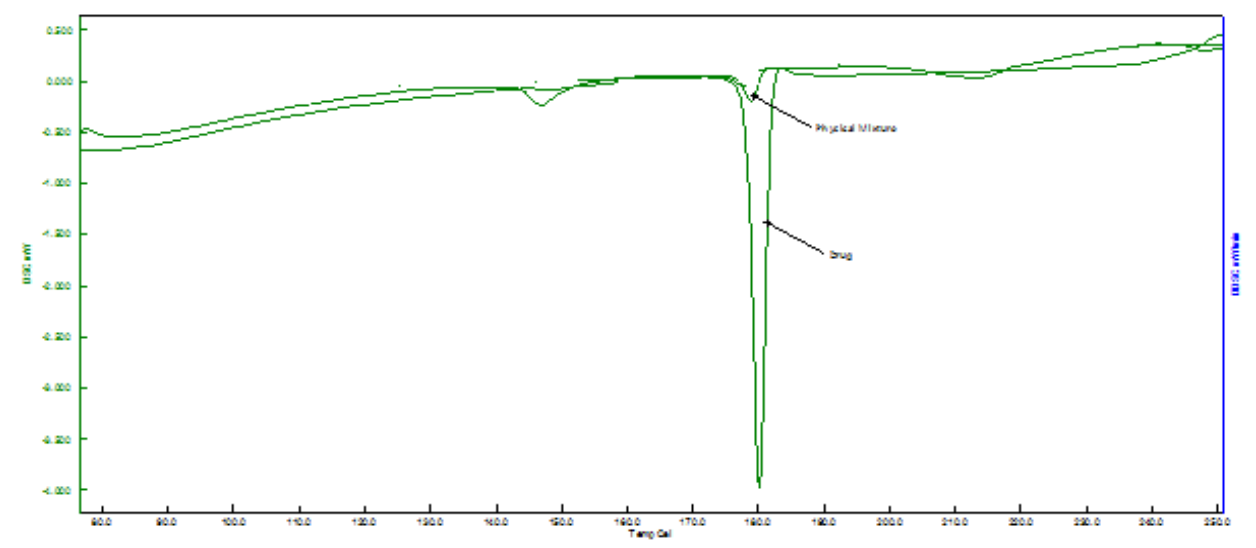

Fig. 2: Overlay of DSC thermogram of promethazine theoclate and physical mixture with excipients

Table 2: Evaluation of promethazine theoclate loaded pellets

\begin{tabular}{|c|c|c|c|c|c|c|}
\hline $\begin{array}{l}\text { Batch } \\
\text { code }\end{array}$ & $\begin{array}{l}\text { Angle of repose } \\
(\theta)^{*}\end{array}$ & $\begin{array}{l}\text { Friability } \\
(\%)^{* *}\end{array}$ & $\begin{array}{l}\text { Particle } \\
\text { size }(\mathrm{mm})^{\$}\end{array}$ & $\begin{array}{l}\text { Disintegration time } \\
\text { (sec) }\left(Y_{1}\right)\end{array}$ & $\begin{array}{l}\text { \% Drug release after } 10 \\
\min \left(\mathrm{Y}_{2}\right)^{\#}\end{array}$ & $\begin{array}{l}\text { Bulk density } \\
(\mathrm{g} / \mathrm{ml})^{*}\left(\mathrm{Y}_{3}\right)\end{array}$ \\
\hline I & $28.35 \pm 0.02$ & $0.57 \pm 0.24$ & $1.41 \pm 0.18$ & 33.89 & $101.71 \pm 0.34$ & $0.71 \pm 0.02$ \\
\hline II & $24.87 \pm 0.03$ & $0.42 \pm 0.02$ & $1.31 \pm 0.23$ & 24.30 & $93.67 \pm 0.27$ & $0.68 \pm 0.03$ \\
\hline III & $23.96 \pm 0.02$ & $0.72 \pm 0.40$ & $1.32 \pm 0.22$ & 23.20 & $93.82 \pm 0.45$ & $0.71 \pm 0.02$ \\
\hline IV & $20.55 \pm 0.02$ & $0.62 \pm 0.16$ & $1.34 \pm 0.24$ & 56.25 & $85.94 \pm 0.40$ & $0.72 \pm 0.02$ \\
\hline V & $25.42 \pm 0.01$ & $0.37 \pm 0.09$ & $1.29 \pm 0.22$ & 40.21 & $82.05 \pm 0.45$ & $0.63 \pm 0.01$ \\
\hline VI & $28.07 \pm 0.01$ & $0.32 \pm 0.35$ & $1.11 \pm 0.24$ & 28.88 & $85.14 \pm 0.59$ & $0.66 \pm 0.01$ \\
\hline VII & $23.80 \pm 0.01$ & $0.43 \pm 0.42$ & $0.87 \pm 0.42$ & 59.00 & $77.43 \pm 0.79$ & $0.65 \pm 0.01$ \\
\hline VIII & $23.90 \pm 0.01$ & $0.80 \pm 0.19$ & $1.01 \pm 0.19$ & 53.08 & $87.75 \pm 0.65$ & $0.59 \pm 0.01$ \\
\hline IX & $24.56 \pm 0.02$ & $0.58 \pm 0.35$ & $1.29 \pm 0.37$ & 21.05 & $100.52 \pm 0.65$ & $0.58 \pm 0.02$ \\
\hline
\end{tabular}

Values are expressed as mean $\pm S D,{ }^{*} n=3, \# n=3,{ }^{* *} n=2,{ }^{\$} n=200$

Disintegration time and percent drug release after 10 min. are the important parameters to be optimized as far as drug release from immediate release pellets is concerned. Bulk density plays a critical role when pellets need to be filled in capsules in order to get correct dose to be delivered.

Disintegration time, percent drug release and bulk density were found to vary with changing concentration of MCC and Corn starch.

To estimate the effect of concentration MCC and Corn starch on disintegration time, percent drug release and bulk density, $3^{2}$ factorial design was investigated. Statistical analysis of data by
ANOVA suggested linear model significant for disintegration time with p-value 0.0102 and quadratic model significant for percent drug release after $10 \mathrm{~min}$. and bulk density with p values 0.0353 and 0.0167 respectively.

Polynomial equations generated by design expert software are explained herewith for its interpretation of effect on response parameters.

Disintegration time $\left(\mathrm{Y}_{1}\right)=37.76+8.62 * \mathrm{X}_{1}-12.67 * \mathrm{X}_{2}$

Positive coefficient of $X_{1}$ in equation (1) indicated increase in the disintegration time $\left(\mathrm{Y}_{1}\right)$ with increase concentration of MCC up to 
certain concentration, and negative coefficient of $\mathrm{X}_{2}$ indicates decrease in its response $\left(\mathrm{Y}_{1}\right)$ with increase in concentration of Corn starch up to certain concentration since Corn starch acts as disintegrating agent, and thereby reduces disintegration time of pellets. The response plot and counterplots in fig. $3 \mathrm{~A}$ and $3 \mathrm{~B}$ respectively are indicative of the relative effect of concentration of MCC and Corn starch on disintegration time of promethazine theoclate loaded pellets.
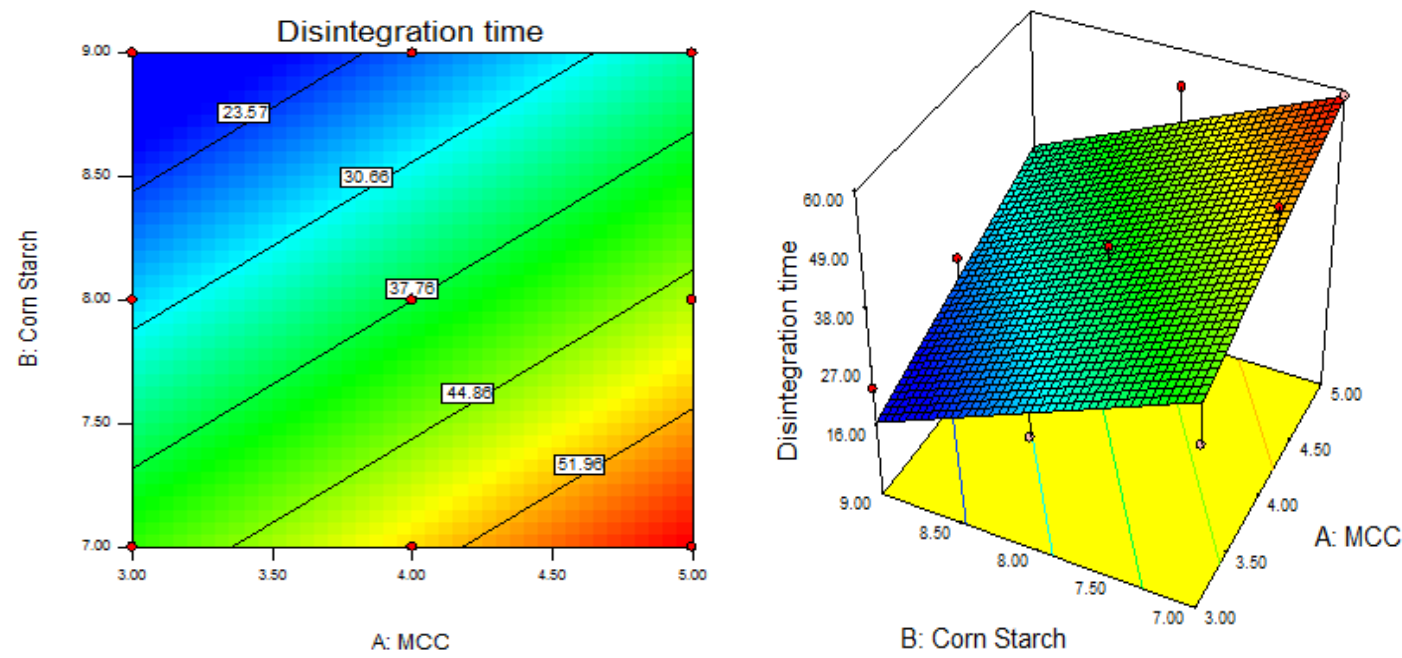

B: Corn Starch

Fig. 3: Different plots showing effect of independent variables on Disintegration time of pellets, (A) Counterplot showing the relationship between various levels of two independent variables, (B) Response surface plot showing the influence of the concentration of MCC and Corn Starch on the Disintegration time

Percent drug release after $10 \min \left(\mathrm{Y}_{2}\right)=82.42$ $3.92 * \mathrm{X}_{1}+2.40 * \mathrm{X}_{2}+7.75 * \mathrm{X}_{1} * \mathrm{X}_{2}+8.11 * \mathrm{X}_{1}^{2}+2.94 * \mathrm{X}_{2}^{2} \ldots$ (2)

From equation (2), it is observed that negative coefficient of $\mathrm{X}_{1}$ indicates a decrease in percent drug release after $10 \mathrm{~min}\left(\mathrm{Y}_{2}\right)$ with an increase in the concentration of MCC whereas the positive coefficient of $X_{2}$ indicates an increase in percent drug release after
10 min with an increase in the concentration of Corn starch till certain concentration level. Increase in Corn starch might be increasing disintegration of pellets leading to faster drug release. The 3D response plot and counterplots indicating the relative effect of concentration of MCC and Corn starch on percent drug release after $10 \mathrm{~min}$ of promethazine theoclate loaded pellets are shown in fig. $4 \mathrm{~A}$ and $4 \mathrm{~B}$ respectively.
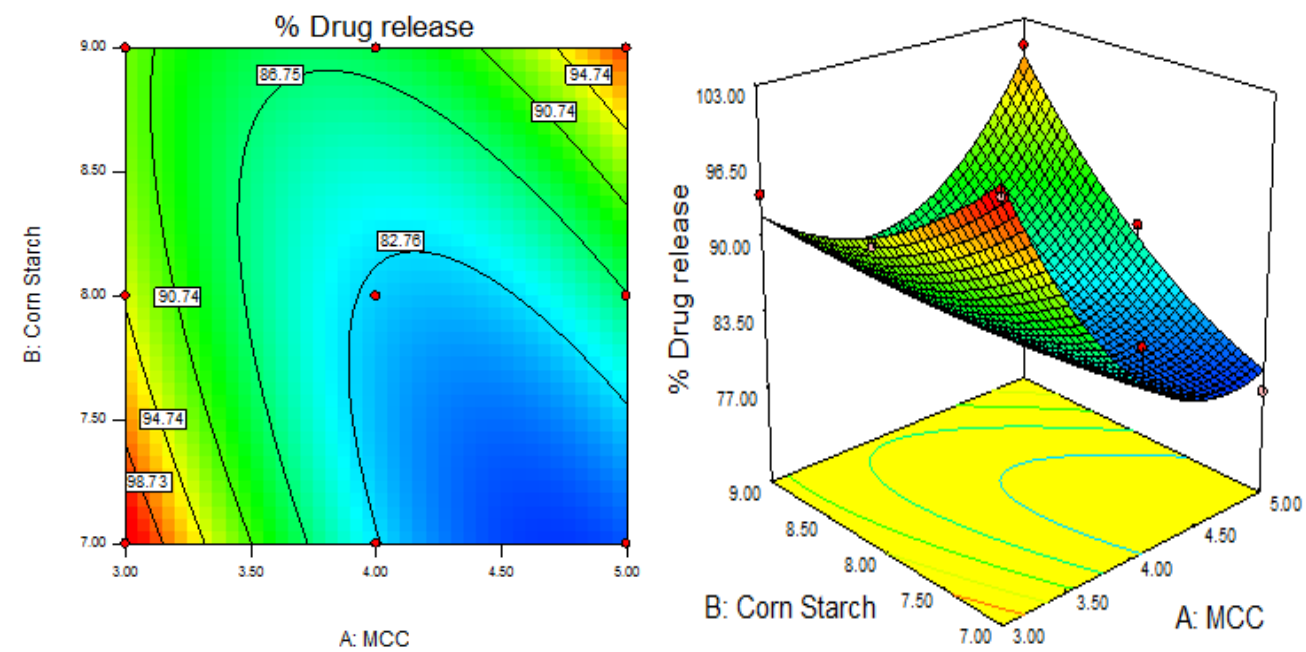

Fig. 4: Different plots showing the effect of independent variables on \% drug release of pellets after 10 min, (A) Counterplot showing the relationship between various levels of two independent variables, (B) Response surface plot showing the influence of the concentration of MCC and Corn Starch on the \% drug release of pellets after $10 \mathrm{~min}$

\section{Bulk density $\left(\mathrm{Y}_{3}\right)=0.64-0.047 * \mathrm{X}_{1}-0.020 * \mathrm{X}_{2-}-0.018 * \mathrm{X}_{1} * \mathrm{X}_{2}$ $0.018 * \mathrm{X}_{1}^{2}+0.037 * \mathrm{X}_{2}^{2} \ldots(3)$}

Equation (3), indicated a decrease in the bulk density ( $\left.\mathrm{Y}_{3}\right)$ with an increase in the concentration of MCC and decrease in bulk density with increase in the concentration of Corn starch up to certain concentration level, might be due to a reduction in the total content of excipients.

The response plot and counterplots are shown in fig. $6 \mathrm{~A}$ and $6 \mathrm{~B}$ respectively which are indicative of a relative effect of concentration of MCC and Corn starch on the bulk density of promethazine theoclate loaded pellets. 

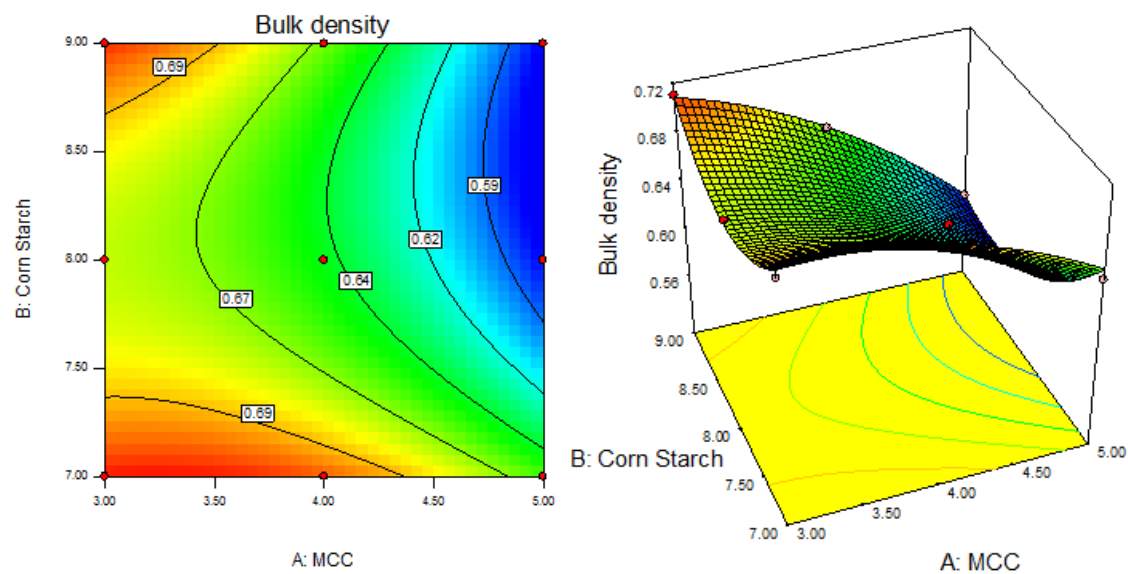

Fig. 6: Different plots showing the effect of independent variables on the bulk density of pellets, (A) Counterplot showing the relationship between various levels of two independent variables, (B) Response surface plot showing the influence of the concentration of MCC and corn Starch on the bulk density of pellets

Though excipients are considered as inactive ingredients, they have a significant impact on functional properties of the formulation. It is known that MCC when extruded to get the dense material, it tends to disintegrate very slowly with the absence of disintegrating agent as well as an increase in the concentration of MCC increases compatibility of powder mixture leading to lower disintegration time [17]

Considering these facts, here increase in the concentration of MCC decreases disintegration time, a decrease in bulk density of pellets. Due to reduced disintegration time, it further leads to decrease in percent drug release. On the contrary, Corn starch being a disintegrant, cause disintegration of pellets by swelling action [18] and thereby enhancing the drug release from pellets.

With reference to the graphical and mathematical analysis of data by experimental design formulation composition of batch IX of promethazine, theoclate was found to give desired results at higher concentrations of MCC, $5 \%$ and Corn starch 9\%.

Optimized formulation was further characterized by SEM analysis to evaluate the morphology of pellets such as pellet shape and surface characteristics.

It was found to have a spherical shape and smooth surface with minimal pores, indicating uniformity in pellets as shown in fig. 7 .

The observed values of optimized batch during the response variables are compared with the predicted values. From the results observed (table 3), it was found that mathematical models generated were statistically significant and valid for predicting values of response parameters at selected levels of formulation variables
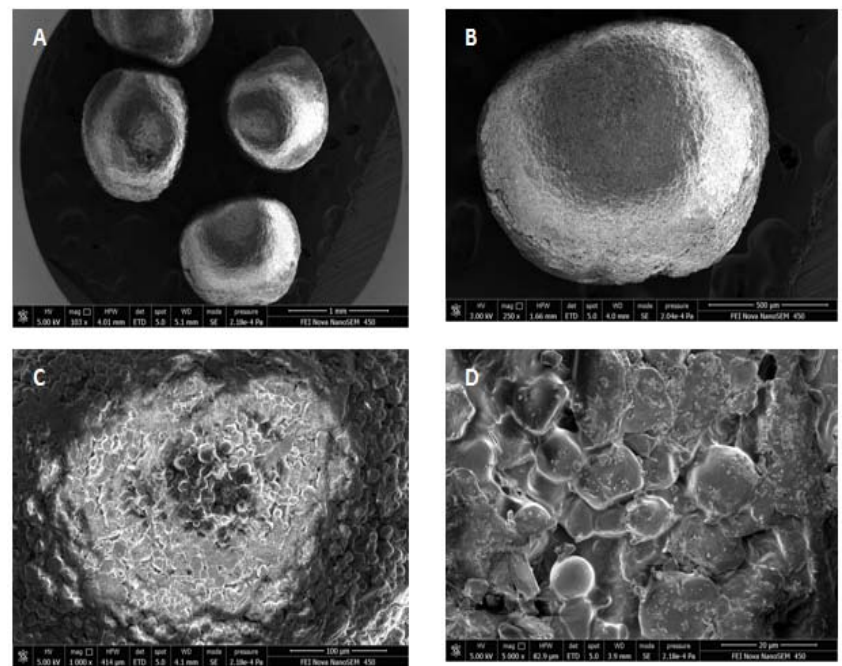

Fig. 7: SEM images of optimized formulation batch IX; A) at $103 \mathrm{X}, \mathrm{B}$ ) at $250 \mathrm{X}, \mathrm{C}$ ) at $1000 \mathrm{X}$, and $\mathrm{D}$ ) at $5000 \mathrm{X}$

Table 3: Validation of optimised formulation (Batch code: IX)

\begin{tabular}{lll}
\hline Parameters & Predicted value & Actual (experimental) value \\
\hline Bulk density $(\mathrm{g} / \mathrm{ml})$ & 0.58 & 0.59 \\
Angle of repose $\left({ }^{\circ}\right)$ & 24.65 & 24.56 \\
Yield $(\%)$ & 71.88 & 78.00 \\
Particle size $(\mathrm{mm})$ & 1.285 & 1.21 \\
Hardness $\left(\mathrm{kg} / \mathrm{cm}^{2}\right)$ & 0.07 & 0.08 \\
Friability $(\%)$ & 0.55 & 0.58 \\
Drug release after 10 min. $(\%)$ & 99.69 & 100.52 \\
\hline
\end{tabular}

An optimized batch of promethazine theoclate pellets (IX) was filled into capsule shell equivalent to a required dose of the drug and it's percent release was compared with the marketed formulation of promethazine theoclate tablet (Avomine tablet). Both formulations showed the comparative release of $>85 \%$ within $30 \mathrm{~min}$. which indicates immediate drug release.
The comparative release profile is shown in fig. 8 .

Stability studies of optimized formulation indicated no significant change in the appearance of pellets, its assay, and disintegration time and percentage drug release after $30 \mathrm{~d}$ of storage at accelerated conditions. 


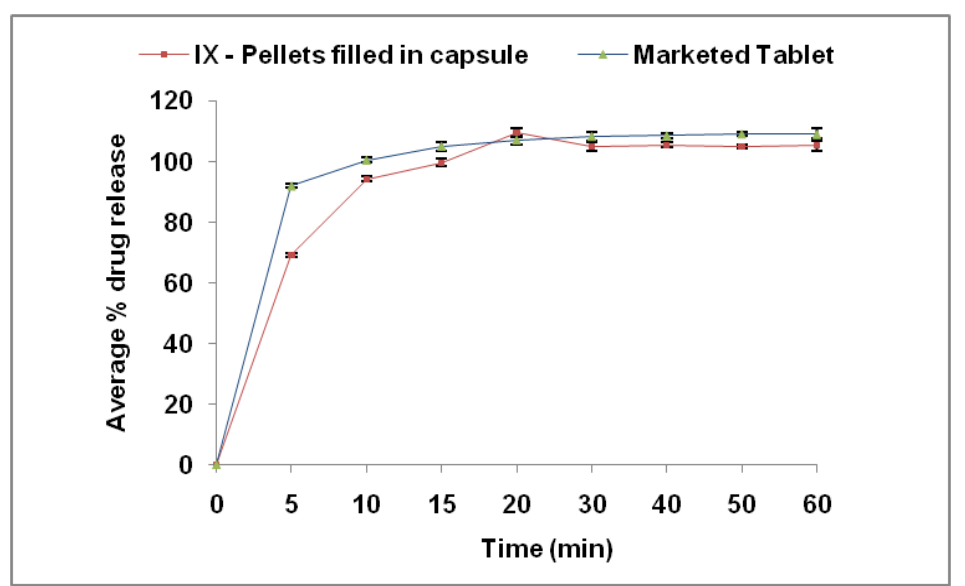

Fig. 8: Comparative percent release profile of optimized formulation of pellets filled in a capsule with the marketed product (Avomine tablet; sanofi aventis)

\section{CONCLUSION}

In the present study, systematic efforts were made to develop and optimize promethazine theoclate loaded immediate release pellets as multiparticulate drug delivery system which can be delivered after filling into a gelatin capsule.

Optimization of the formulation was demonstrated by using $3^{2}$ full factorial design and investigation using polynomial equations, surface response plots and counterplots generated during the investigation. Optimised formulation (IX) was found to show highest percent yield of 91.4 , the bulk density of $0.58 \pm 0.02 \mathrm{~g} / \mathrm{ml}$ with good flow properties having a $24.56 \pm 0.02{ }^{\circ}$ angle of repose, $0.58 \pm 0.35 \%$ friability, and disintegration time of 21.05 seconds. The particle size of optimized formulation was found to be $1.29 \pm 0.37 \mathrm{~mm}$ with $100.52 \pm 0.65 \%$ drug release after $10 \mathrm{~min}$. Promethazine theoclate loaded pellets showed the significant effect of independent variables i.e. concentration of MCC and Corn starch on dependent variables i.e. bulk density, disintegration time and percent drug release after 10 min which are critical parameters in terms of dosage, disintegration and drug release respectively when pellets are to be delivered into the capsule. Percent drug release of optimized formulation (IX) was found to be comparable with marketed formulation (Avomine Tablet). Optimized formulation (IX) was found to be stable at $40{ }^{\circ} \mathrm{C}$ and $75 \% \mathrm{RH}$ after $30 \mathrm{~d}$ of storage.

Promethazine theoclate pellets formulated in this study can be used as an alternative to tablet dosage form which can give immediate drug release for treatment of motion sickness and post-operative emesis.

\section{ACKNOWLEDGEMENT}

We are thankful to Mehta Pharmaceutical, Mumbai for providing the gift sample of promethazine theoclate.

\section{AUTHORS CONTRIBUTIONS}

All the authors have contributed equally.

\section{CONFLICTS OF INTERESTS}

All authors have none to declare

\section{REFERENCES}

1. Sanders-Bush E, Hazelwood L, Brunton LL, Chabner BA, Knollmann BC. Goodman and Gilman's the pharmacological basis of therapeutics. McGraw-Hill Medical New York; 2011.

2. Kumar P, Tiwari A, Chhabra Gand, Pathak K. Use of central composite design for statistical optimization promethazine theoclate loaded solid lipid nanoparticles. Asian J Pharm 2014;8:279-86.

3. Vats SK, Gupta RN, Kalaiselvan R, Singh R. Design and statistical evaluation of a multiunit delivery system containing nisoldipine-soluplus ${ }^{\circledR}$ solid dispersion for hypertension chronotherapy. Int J Pharm Sci 2016;10:170-7.

4. Sharma S, Sharma N, Gupta G. Formulation of fast-dissolving tablets of promethazine theoclate. Trop J Pharm Res 2010;9:489-97.

5. Latha S, Selvamani P, Thirunavukkarasu C, Pal TK, Ghosh LK. Development and comparative evaluation of a trans dermal therapeutic system for antiemetic therapy. Asian J Chem 2011;23:5267-70

6. Cantisani C, Ricci S, Grieco T, Paolino G, Faina V, Silvestri E. Topical promethazine side effects: our experience and review of the literature. BioMed Res Int 2013;9. http://dx.doi. org/10.1155/2013/151509

7. Nalanda TR, Prashant KP. Development of multiparticulate formulation and evaluation of colon targeted drug delivery system of ciprofloxacin: in vivo study with induced colitis model in rats. Asian J Pharm Clin Res 2017;10:167-85.

8. Doniparthi B, Jeevana J. multiparticulate drug delivery systems using natural polymers as release retardant materials. Int J Pharm Pharm Sci 2014;6:61-5.

9. Tomer G, Patel H, Podczeck F, Newton JM. Measuring the water retention capacities (MRC) of different microcrystalline cellulose grades. Eur J Pharm Sci 2001;12:321-5.

10. Rahman MA, Ahuja A, Baboota S, Bali V, Saigal N, Ali J. Recent advances in pelletization technique for oral drug delivery: a review. Curr Drug Delivery 2009;6:122-9.

11. O'Connor RE, Schwartz JB. Spheronization II: drug release from drug-diluent mixtures. Drug Dev Ind Pharm 1985;11:1837-57.

12. Okada S, Nakahara H, Isaka H. Adsorption of drugs on microcrystalline cellulose suspended in aqueous solutions. Chem Pharm Bull 1987;35:761-8.

13. Rivera SL, Ghodbane S. In vitro adsorption-desorption of famotidine on microcrystalline cellulose. Int J Pharm 1994;108:31-8.

14. Otero-Espinar FJ, Luzaro-Alvarez A, Blanco-Mendez J. Non-MCC materials as extrusion-spheronization aids in pellets production. J Drug Delivery Sci Technol 2010;20:303-18.

15. Cherian C, Arnepalli D, Dogga N, Raviteja NB, Gorie SV. Assessment of grain size and pore size distribution using digital image analysis: proceedings of indian geotechnical conference IGC, Indian Institute of Technology Madras, Kakinada India; 2014.

16. Chamsai B, Pornsak S. Novel disintegrating microcrystalline cellulose pellets with improved drug dissolution performance. Powder Technol 2013;233:278-85.

17. Gregory T, Fabrice K, Bruno L, Brian C, Brigitte E. Microcrystalline cellulose, a direct compression binder in a quality by design environment-a review. Int J Pharm 2014;473:64-72.

18. Parind MD, Celine VL, Paul WSH. Review of disintegrants and the disintegration Phenomena. J Pharm Sci 2016;105:2545-55. 